\title{
Radiofrequency ablation leading to ST-segment elevation: a case report
}

\author{
Ivica Benko*, \\ Šime Manola, \\ Tomislav Krčmar, \\ Nikola Pavlović, \\ Ivan Zeljković, \\ Vjekoslav Radeljić, \\ Gordana Hursa, \\ Sanja Keleković
}

University Hospital Center "Sestre milosrdnice", Zagreb, Croatia

RECEIVED:

February 7, 2016

ACCEPTED:

February 20, 2016

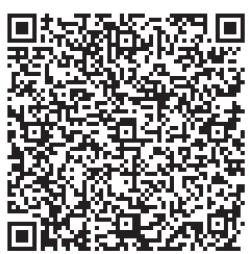

$\square$ Cardiologia Croatica 2016;11(3-4):96.
KEYWORDS: ablation, ventricular tachycardia, ST-segment elevation.

CITATION: Cardiol Croat. 2016;11(3-4):96. | Dol: http://dx.doi.org/10.15836/ccar2016.96

*ADDRESS FOR CORRESPONDENCE: Ivica Benko, Klinički bolnički centar Sestre milosrdnice, Vinogradska 29, HR-10000 Zagreb, Croatia. / Phone: +385-1-3787-312 / E-mail: ivica.benko@kbcsm.hr

ORCID: Ivica Benko, http://orcid.org/0000-0002-1878-0880 • Šime Manola, http://orcid.org/0000-0001-6444-2674 Tomislav Krčmar, http://orcid.org/0000-0003-4689-1673 • Nikola Pavlović, http://orcid.org/0000-0001-9187-7681 Ivan Zeljković, http://orcid.org/0000-0002-4550-4056 • Vjekoslav Radeljić, http://orcid.org/0000-0003-2471-4035 Gordana Hursa, http://orcid.org/0000-0001-9118-9707 • Sanja Keleković, http://orcid.org/0000-0003-4951-876X

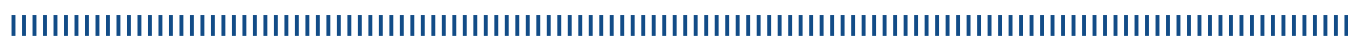

Nowadays, ablation treatment of ventricular tachycardia is more and more common, whether it is on structural-diseased or normal heart. ${ }^{1}$

We report the case of a 47-year old female patient in whom an electrophysiology study (EP) with 3D mapping system (CARTO) was performed due to paroxysmal idiopathic sustained ventricular tachycardia (VT). Anterograde as well as retrograde approach was used during the procedure and fascicular VT using left posterior fascicle was diagnosed, however it was rather non-sustained. After 90 minutes of mapping, patient complained of chest pain and sustained VT was recorded in 12-lead electrocardiogram. After short conversion to sinus rhythm an ST-segment elevation in anterior leads was noticed. The EP procedure was aborted and coronary angiography was performed. Coronary angiography showed dissection of ostial left anterior descending artery and percutaneous coronary intervention with implantation of 2 drug-eluting stents was performed.

After 3 months follow up, echocardiography showed normal left ventricular systolic function (EF 60\%) with mild hypokinesia of the anteroseptal region. With verapamil as antiarrhythmic therapy the patient was free of VT during 6 months and without heart failure symptoms.

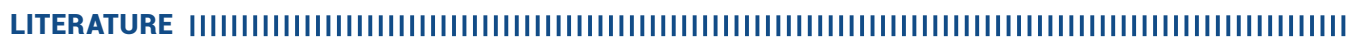

1. Lerman BB, Stein KM, Markowitz SM. Mechanisms of idiopathic left ventricular tachycardia. J Cardiovasc Electrophysiol. 1997;8(5):571-83. DOI: http://dx.doi.org/10.1111/j.1540-8167.1997.tb00826.x 